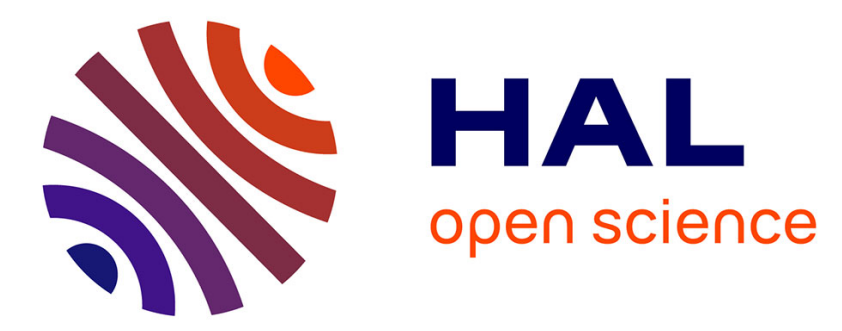

\title{
Catalysts supported by homochiral molecular helices: a new concept to implement asymmetric amplification in catalytic science
}

Yan Li, Laurent Bouteiller, Matthieu Raynal

\section{- To cite this version:}

Yan Li, Laurent Bouteiller, Matthieu Raynal. Catalysts supported by homochiral molecular helices: a new concept to implement asymmetric amplification in catalytic science. ChemCatChem, 2019, 10.1002/cctc.201901246 . hal-02303651

\section{HAL Id: hal-02303651 \\ https://hal.sorbonne-universite.fr/hal-02303651}

Submitted on 3 Oct 2019

HAL is a multi-disciplinary open access archive for the deposit and dissemination of scientific research documents, whether they are published or not. The documents may come from teaching and research institutions in France or abroad, or from public or private research centers.
L'archive ouverte pluridisciplinaire HAL, est destinée au dépôt et à la diffusion de documents scientifiques de niveau recherche, publiés ou non, émanant des établissements d'enseignement et de recherche français ou étrangers, des laboratoires publics ou privés. 


\title{
Catalysts supported by homochiral molecular helices: a new concept to implement asymmetric amplification in catalytic science
}

\begin{abstract}
Yan Li, ${ }^{[a]}$ Laurent Bouteiller, ${ }^{[a]}$ Matthieu Raynal ${ }^{[[a]}$
Abstract: Connecting intrinsically achiral catalytic centres to helical polymers provides a new class of asymmetric catalysts whose selectivity exclusively stems from the chiral environment provided by the helical polymer. Chirality amplification phenomena allow to control the handedness and the helical sense excess of these polymers which in turn dictate the stereochemical direction and the extent of enantioinduction, respectively, obtained in the course of the asymmetric reaction. This minireview is focused on such helical catalysts built either on a covalent or a non-covalent scaffold and for which the handedness is controlled by an asymmetric polymerization reaction, by enantiopure monomers or by chiral additives. The selectivity of catalysts based on a dynamic helical backbone can be controlled by changing the solvent or with additives. The fact that the enantiomeric state of such asymmetric catalysts can be switched in a predictable way is particularly emphasized.
\end{abstract}

\section{Introduction}

Asymmetric homogenous catalysis is the ubiquitous method for the preparation of optically active compounds. This is because in this process a catalytic amount of a well-designed chiral nonracemic species is able to assemble prochiral/achiral reagents and generate multiple copies of a chiral molecule, preferentially in the form of a single enantiomer. Since major breakthroughs achieved in the early 1970s, great effort has been devoted to the development first of enantiopure ligands and organometallic catalysts ${ }^{[1]}$ and later on of chiral organocatalysts, ${ }^{[2]}$ for a plethora of reactions and compounds, many of them being of industrial interest. Alongside with optimizing reaction parameters (e.g. catalytic loading and selectivity), minimizing the catalyst cost is desirable for practical applications. Along this line, harnessing asymmetric processes that get rid of or minimize the need of an enantiopure chemical species is currently under exploration by means of a variety of physical and chemical approaches. ${ }^{[3]}$

In the context of catalytic sciences, the term asymmetric amplification $^{[4]}$ almost exclusively refers to reactions whose enantioselectivity is higher than the one calculated by considering only the optical purity of the catalyst. ${ }^{[5]}$ In other words, the apparent optical purity of the ligand or organocatalyst ${ }^{[6]}$ is enhanced during the enantiodiscriminating step. Strong positive non-linear effects (NLE) are observed when a mixture of enantiopure ligands that is only slightly biased from the racemic mixture yields an enantioenriched product. The study of NLE emerged as a powerful mechanistic tool to probe the nature of the active species, mainly in the context of asymmetric organometallic reactions. ${ }^{[7]}$ Alternatively, chiral nonracemic additives are commonly employed to perform asymmetric reactions with otherwise racemic catalysts. ${ }^{[8]}$ As an extreme case of asymmetric amplification, the Soai reaction produces a highly enantioenriched pyrimidyl alkanol from addition of diisopropylzinc to the respective aldehyde in presence of a nearly racemic seed or of various chiral environments. ${ }^{[9]}$ The formation of tetramer or higher oligomer structures might explain the incredibly high level of amplification

[a] Sorbonne Université CNRS, Institut Parisien de Chimie Moléculaire, Equipe Chimie des Polymères, 4 Place Jussieu, 75005 Paris (France) matthieu.raynal@upmc.fr. observed in this reaction ${ }^{[10]}$ and in related autocatalytic (or autoinductive) asymmetric processes. ${ }^{[11]}$

The previous statement infers a connection between asymmetric amplification and catalyst aggregation and indeed, chirality amplification phenomena are ubiquitous in polymer science and in molecular self-assembly. In these fields, chiral amplification refers to the control of the main chain helicity of the macro/supramolecule by means of cooperative (minute) conformational biases induced by the monomers. ${ }^{[12]}$ These phenomena might arise when a new element of chirality is created upon the polymerization or assembly of monomers. In the 80 s-90s, Green and co-workers intensively investigated the occurrence of such effects for covalent poly(isocyanate)s, ${ }^{[12 a]}$ i.e. polymers with a main chain that adopts a stable but dynamic helical conformation in solution. ${ }^{[13]}$ Single-handed helices can be obtained not only from homopolymers of enantiopure monomers but also from copolymers consisting of a mixture of enantiopure ("sergeants") and achiral ("soldiers") monomers. The so-called "sergeants-and-soldiers" (S\&S) effect ${ }^{[14]}$ arises when a minor amount of sergeants is able to control the local conformation of an excess of soldiers that cannot escape this influence except through rarely occurring helix reversals. The same explanation is also valid for a non-racemic (i.e. scalemic) mixture of enantiomeric monomers in which the major enantiomer controls the main helicity of the polymer and accordingly such effect is named as "majority-rules" (MR). ${ }^{[15]}$ Combining the sergeantsand-soldiers and majority-rules effects is possible in the case of terpolymers composed of achiral monomers and a scalemic mixture of monomers ("diluted majority-rules"). In this context, it is also important to mention the possibility of controlling the main chain helicity of polymers such as poly(triphenymethyl methacrylate)s ${ }^{[16]}$ and poly(quinoxaline-2,3-diyl)s ${ }^{[17]}$ by asymmetric polymerization since here also the local conformation of many achiral monomers can be imposed by a single chiral inducer or catalyst. Chiral additives, which are not units of the polymer chain, can also be used to lock the handedness of the helix, which can eventually be kinetically memorized after their removal (macromolecular helical memory). Finally, chiral solvents or physical fields ${ }^{[18]}$ constitute alternative and potentially cost-effective approaches to generate homochiral helices. ${ }^{[19]}$ Whilst helix sense-selective reactions have been restricted to a few classes of covalent polymers, ${ }^{[20]}$ chirality 
a)

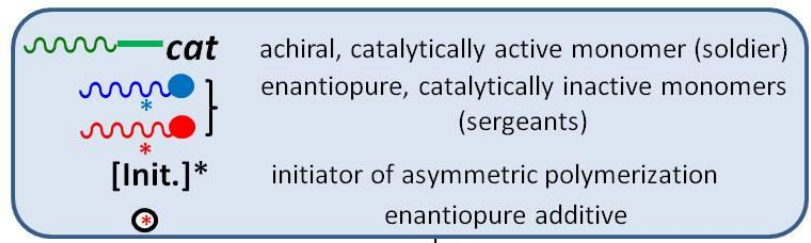

Method A: Through asymmetric polymerization

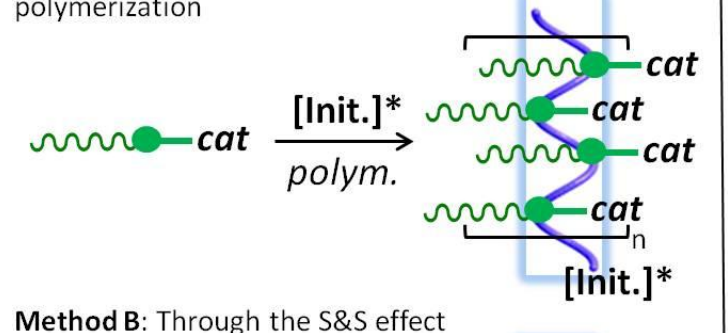

Method C: Through the diluted MR effect

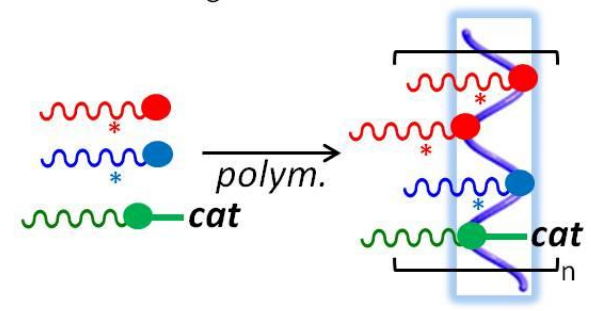

Method D: Through chiral additives

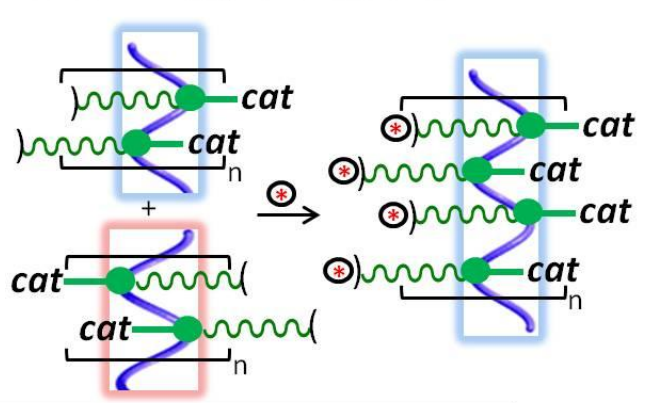

b)

\section{poly-Mxx}

$M$ : nature of the polymer: $M A=$ methacrylate, $\mathrm{DI}=$ diisocyanide, $I C=$ isocyanate, $\mathrm{PA}=$ phenylacetylene, $\mathrm{PI}$ = phenylisocyanide, $\mathrm{BTA}$ = benzene-1,3,5-tricarboxamide $\boldsymbol{x} \mathbf{x}:$ monomer type: $P P h 2=$ phosphine-functionalized monomer, $N=$ nitrogenfunctionalized monomer, $c=$ chiral non-racemic non-catalytically active monomer, $a c=$ achiral non-catalytically active monomer

yy: average number of monomers in the macromolecule

for copolymers: - co- = statistical copolymers, - block- = block copolymers

Figure 1 a) Different methods to prepare helical catalysts with a chirally-amplified backbone. This minireview focuses on molecular helices made from achiral monomers used as catalytic sites for an asymmetric reaction. In these systems, the selectivity stems uniquely from the chiral environment provided by the helices prepared according to methods A-D. The purple helix represents a covalent or a non-covalent backbone. Asymmetric catalysis with helical peptides, ${ }^{[21]}$ with $\mathrm{DNA}^{[22]}$ and G-DNA ${ }^{[23]}$ hybrids, with chiral catalysts connected to helical polymers ${ }^{[24]}$ and with achiral catalytic sites embedded in discrete helical scaffolds ${ }^{[25]}$ is out of the scope of this minireview. ${ }^{[26]}$ b) Nomenclature used in this minireview for the different types of helical catalysts.

amplification through the S\&S, MR and diluted MR effects have also been observed in self-assemblies, particularly in supramolecular polymers adopting a helical structure. ${ }^{[13 \mathrm{~b}, 27]}$

In the conclusion of his seminal review on chirality amplification in macromolecules in 1999, ${ }^{[12 a]} \mathrm{M}$. Green questioned whether it can be envisaged to "design a catalytic helical polymer directed to asymmetric synthesis in which the enantiomeric excess of the products were independent, over a wide range, of the enantiomeric excess of the units making up the polymer?". In this minireview, we will show that indeed, a range of helical covalent and supramolecular catalytic polymers ${ }^{[6]}$ have been developed which deliver optically-active products with a selectivity that is, in a certain range, neither related to optical purity of the monomers nor to the number of chiral units constituting the helix. The necessary condition for such an achievement is that intrinsically achiral catalytically-active monomers, instead of chiral non-racemic catalysts in the case of
NLE, are embedded in a helical macromolecule. The handedness of these polymers is controlled by means of chirality amplification effects mentioned above (Figure 1a): (I) asymmetric polymerization (method A), (ii) the S\&S effect (method B), (iii) the diluted MR effect (method C) or (iv) helicity induction by means of chiral additives (method D). Here, the stereochemical direction of the reaction is related to the handedness of the supporting helix (macro/supramolecular chirality) not to the stereogenic centres endowed in the monomeric units (central chirality). Examples illustrating these criteria will be sorted firstly according to the covalent or noncovalent nature of their scaffolds, secondly by the method (A-D) implemented to control the handedness of the helix and finally by the chemical nature of the macromolecule (see the used nomenclature in Figure 1b). Helical catalysts whose enantioselectivity can be reversed or tuned by means of solvent or chemical additives will be put forward in a specific section. 


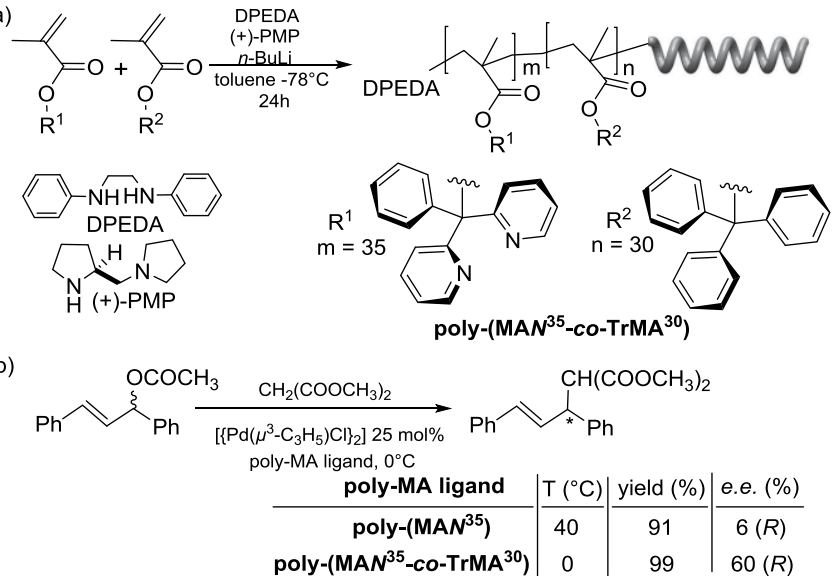

Figure 2 Asymmetric Pd-catalyzed allylic substitution reaction with a catalytic helical poly-(MA). ${ }^{[28]}$ a) Synthetic scheme for the preparation of a catalytic poly-(MA) by asymmetric polymerization and its formula. b) Result obtained in the allylic substitution reaction. The handedness of the helical catalyst has not been determined.

\section{Chirally-amplified covalent catalysts}

\subsection{Through asymmetric polymerization}

Asymmetric polymerization reactions which rely on welldesigned chiral initiators and catalysts have been employed for the preparation of covalent helical polymers with a preferred handedness. A textbook example in the field is the anionic polymerization of triphenymethyl methacrylate (TrMA) with (-)sparteine- $n$-Bu-Li(III) complex as chiral catalyst which yields isotactic and optically active poly-(TrMA) as a consequence of the helical conformation adopted by the polymer backbone. ${ }^{[16]}$ Building on this approach, Reggelin and co-workers investigated in 2002 the possibility of using structurally-related polymers as scaffolds for asymmetric reactions. MA monomers with pyridine rings were polymerized with a mixture of DPEDA $/(+)-P M P / n-$ BuLi which were optically active even though they were initiated by the achiral DPEDA moiety (Figure 2). ${ }^{[28-29]}$ Upon mixing with a $\mathrm{Pd}$ precursor, these helical polymers catalyzed an allylic substitution reaction with good activity but modest enantioselectivity. ${ }^{[29 a]}$ The most efficient catalyst of this series was obtained by copolymerization of MAN and TrMA. The 1:1 copolymer, poly- $\left(\mathrm{MAN}^{35}-\mathrm{co}-\mathrm{TrMA}^{30}\right)$, yielded the product of the substitution with $60 \%$ e.e.. ${ }^{[28]}$ These seminal studies demonstrated that, in the ideal case, multiple homochiral catalytic sites might be generated from one chiral inducer thus amplifying the number of chiral catalytic units. However, the limited conformational stability and the difficult functionalization of the poly-(MA) backbone seriously limited the scope and efficiency of this class of polymer catalysts. ${ }^{[28,29 b]}$

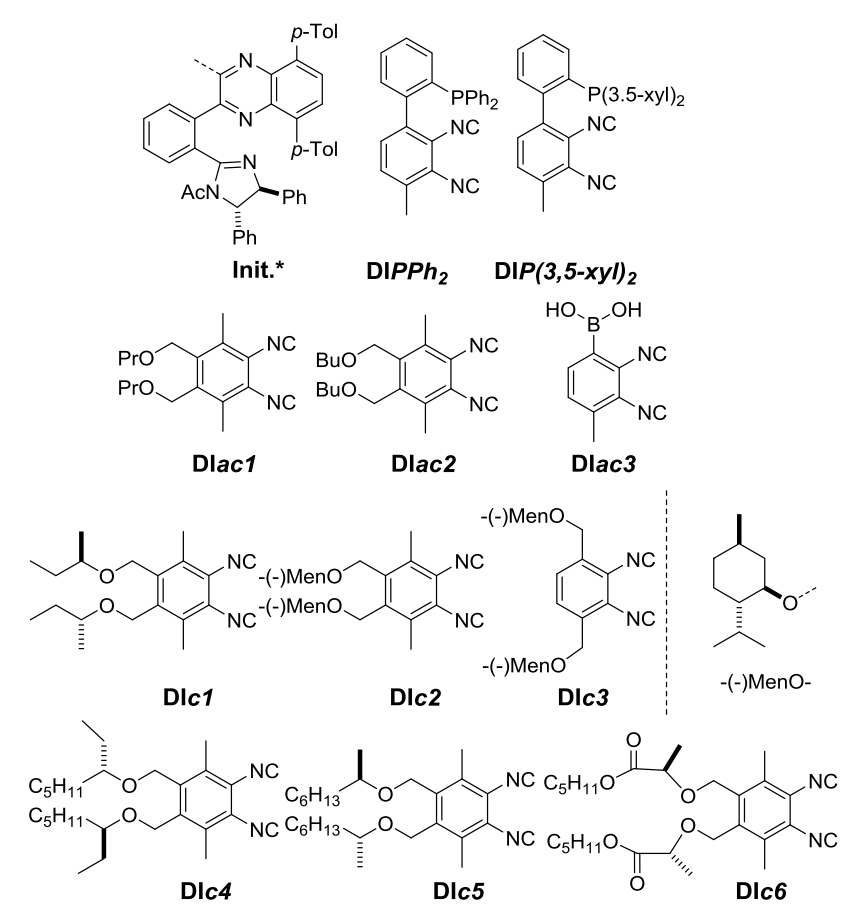

Figure 3 Chemical structures of the chiral initiator and the DI monomers used to prepare the $P Q X$ ligands mentioned throughout this minireview.

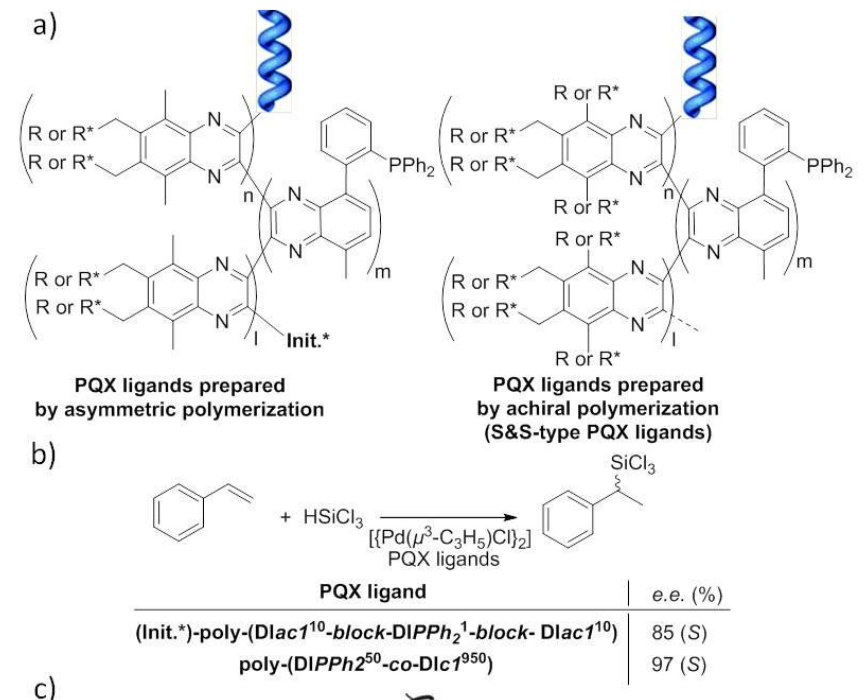

c)

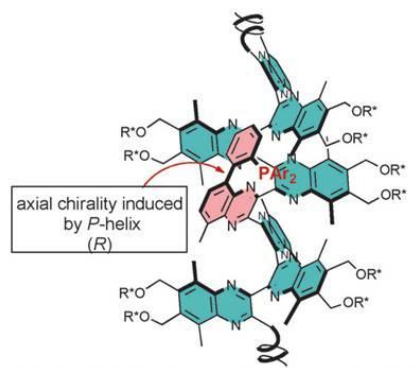

Figure 4 Asymmetric palladium-catalysed hydrosilylation of styrene with $\mathrm{PQX}$ ligands. ${ }^{[30]}$ a) General formula of the $P Q X$ ligands (see the chemical structures of all monomers in Fig.3). b) Result obtained in the hydrosilylation reaction. c) Proposed stereochemical model for the transfer of chirality (central to helical to axial) in PQX ligands. Reproduced with permission from Angew. Chem. Int. Ed., 2011, 50, 8844-8847. Copyright 2011, Wiley-VCH. 
In 2009, building on well-established procedures for the helixsense selective and living polymerization of diisocyanide (DI) monomers, Suginome and co-workers ${ }^{[17,31]}$ reported on the copolymerization of the phosphine-functionalized monomer DIPPh and non-functionalized monomer Dlac1 in the presence of a chiral organopalladium initiator, Init. ${ }^{*} \mathrm{Pd}\left(\mathrm{PPhMe}_{2}\right) \mathrm{I}$ (Figures 3 and 4a). ${ }^{[30 a]}$ Poly (quinoxaline-2,3-diyl) (PQX) block copolymers of the type (Init.*)-poly-(Dlac1-block-DIPPh 2 -block-Dlac1) were prepared which differed by the number of units of the different blocks. In spite of the presence of a single chiral unit located at the extremity of the polymer chain, the resulting copolymers exhibited a stable helical conformation (at r.t.) and a preferred handedness as quantified by a screw-sense excess ${ }^{[32]}$ superior to $90 \%$. Copolymers with a single phosphine unit surrounded by two Dlac1 blocks provided the best result in the presence of a palladium precursor for the hydrosilylation of styrene (Figure $4 \mathrm{~b}$ ) and styrene derivatives (up to $98 \%$ yield and $87 \%$ e.e.). The stereochemical direction of the catalytic reaction is fully controlled by the handedness of the polymers as demonstrated by similar but opposite configuration of the products obtained by $(P)$ - and $(M)$-PQXs. These results were remarkable both in terms of the level of enantioinduction achieved in an asymmetric reaction with helical polymers and the extent of chirality amplification since a single chiral group was enough to control the chiral conformation of 21 achiral units including one that was catalytically active. The high enantiodiscrimination ability of this family of $P Q X$ ligands has been attributed to efficient chirality transfer between the helical polymer main chain and the axis of chirality supporting the $\mathrm{PPh}_{2}$ group (Figure 4c). ${ }^{[30 \mathrm{~b}, 33]}$

Polymers with high molecular weights are required not only for facilitating their recycling and reusability but also for exalting their chiral amplification properties. However, chiral initiators usually fail to control the handedness of long polymer chains and even for the relatively short ones the helical induction might not be optimal. For instance, a 1000 mer-based random copolymer of DIPPh $h_{2}$ and Dlac1, (Init. *)-poly-(DIPPh ${ }^{50}$-coDlac $1^{950}$ ), which only had the chiral terminal group as a source of screw-sense induction was a poorly selective ligand. ${ }^{[0 b]} \mathrm{A}$ more suitable strategy to generate high molecular weight and single-handed PQX ligands relies on mixing achiral and chiral monomers, through the sergeants-and-soldiers approach.

\subsection{Through the S\&S and dilute MR effects}

Living polymerization reactions between achiral catalytically active monomers (the soldiers) and chiral non-racemic catalytically inactive monomers (the sergeants) constitute a facile and easily tunable method for the preparation of dynamic helical catalysts. One important challenge in this strategy is to maintain a good level of enantioinduction because any achiral catalysts that will not be located in the chiral environment provided by the helical polymer scaffold will significantly decrease the selectivity of the reaction. Seminal studies on the induction of a stable and single helical configuration by means of a few percent of sergeants traced back to $1989 .{ }^{[14]}$ However, it is only recently that efficient sergeants-and-soldiers (S\&S) type helical polymers for asymmetric catalysis have been disclosed in the literature.

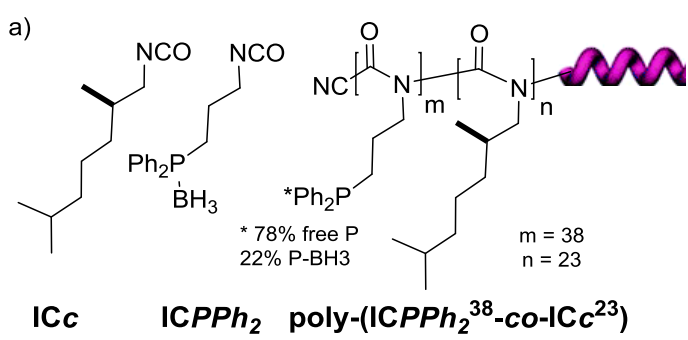

b)

$$
\begin{aligned}
& \text { Ph } \overbrace{\mathrm{NHAc}}^{\mathrm{COOH}} \underset{\left[\mathrm{Rh}(\operatorname{cod})_{2}\right] \mathrm{OTf} 1 \mathrm{~mol} \%}{\mathrm{Ph}} \overbrace{\mathrm{NHAc}}^{\mathrm{COOH}} \\
& \mathrm{H}_{2}(1 \mathrm{~atm}) \text {, r.t. }
\end{aligned}
$$

\begin{tabular}{|c|c|}
\hline & \\
\hline poly-(ICPPh ${ }_{2}^{38}-c 0$ & $>99$ \\
\hline
\end{tabular}

Figure 5 Asymmetric rhodium-catalysed hydrogenation catalyzed by a S\&Stype helical poly-(IC). ${ }^{[28]}$ a) Chemical structure of the IC monomers and of the polyisocyanate ligand. b) Result obtained in the hydrogenation reaction.

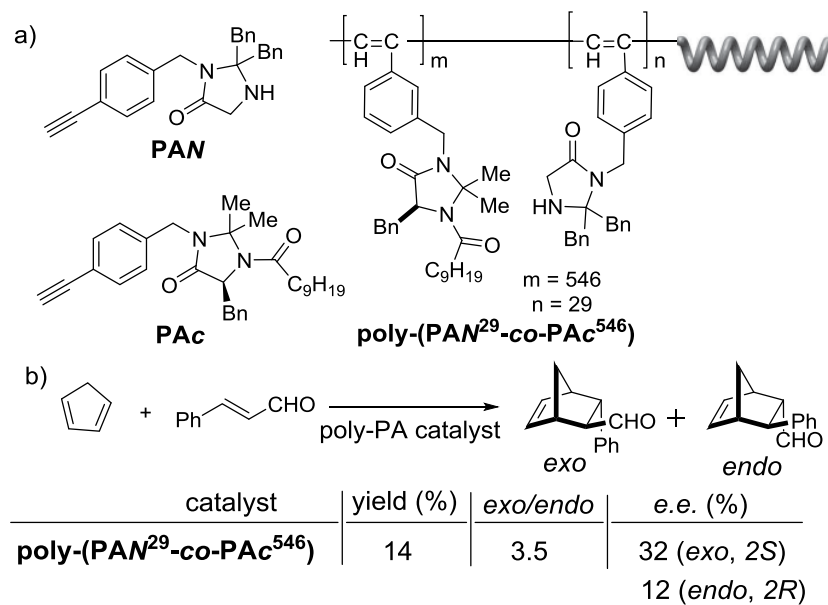

Figure 6 Asymmetric Diels-Alder reaction catalysed by S\&S-type helical poly(PA)s. ${ }^{[34]}$ a) Chemical structure of the PA monomers and of the polyacetylene catalyst. b) Result obtained in the Diels-Alder reaction. The handedness of the helical catalyst has not been determined.

Green and co-workers demonstrated that $15 \%$ of a chiral nonracemic isocyanate monomer (ICc, sergeant) was enough to get single handed polyisocyanate when co-polymerized with an achiral isocyanate monomer (soldier) ${ }^{[14]}$ In 2004, Reggelin and co-workers attempted to design a catalytic version of these S\&Stype polymers by mixing $\mathrm{IC} c$ with a phosphine-functionalized monomer (ICPPh , Figure 5). When coordinated to rhodium, polymer poly-(ICPPh$\left.{ }^{38}-\mathrm{Co}-\mathrm{ICC} c^{23}\right)$ proved to catalyze the hydrogenation of $\mathrm{N}$-acetamidocinnamic acid efficiently (conversion>99\%) but with low enantioselectivity (15\% e.e.). ${ }^{[28]}$ More recently, Yashima and co-workers prepared a range of helical poly(phenylacetylene)s, poly-(PA)s, composed of chiral and achiral PA monomers endowed with different imidazolinone side chains. ${ }^{[34]}$ The achiral monomer contained a basic secondary amine which is known to activate carbonyl compounds while the chiral monomer embedded a cyclic tertiary amide moiety and was thus catalytically inactive. After screening the influence of the structure of a range of monomers on the rate and selectivity of a Diels-Alder reaction of reference, they 


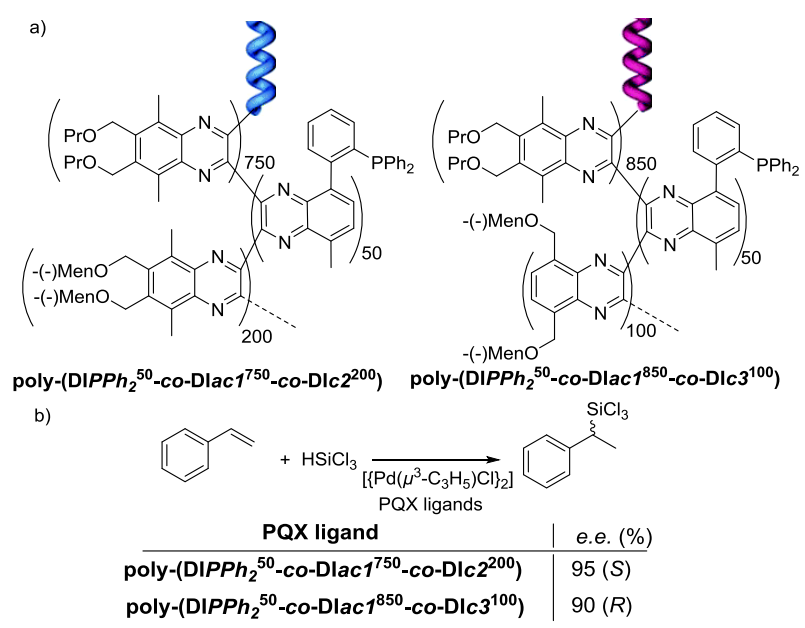

Figure 7 Asymmetric palladium-catalysed hydrosilylation of styrene with $P Q X$ ligands derived from (-)-menthol. ${ }^{[35]}$ a) Structure of the PQX ligands. b) Result obtained in the hydrosilylation reaction.

established that the random copolymers incorporating achiral PAN and chiral non-racemic PAC monomers provided the best enantioselectivity (Figure 6). Poly-(PAN ${ }^{29}-C o-P A c^{546}$ ) with $95 \%$ of PAc furnished the Diels-Alder adduct with unusual exo selectivity (exo/endo=3.5) and modest enantioselectivities (32\% e.e. and $12 \%$ e.e. for exo and endo products, respectively). The non-helical version of this copolymer, obtained upon isomerization of the PA backbone upon grinding, was almost non-selective which demonstrated that the macromolecular helicity (not the chiral side chains) dictated the selectivity outcome of the reaction. Lowering the fraction of chiral monomers in the copolymer resulted in a non-linear decrease of the enantioselectivity, yet the highest enantioselectivity was obtained for the copolymer containing as much as $95 \%$ chiral monomers.

Far higher degree of enantioselection has been reported with sergeants-and-soldiers type PQXs ligands. A 1000 mer-based PQX ligand obtained by copolymerization of DIPPh $2(5 \%)$ and DIc1 (95\%) with an achiral organonickel initiator furnished the hydrosilylation product with $97 \%$ e.e. (Figure $4 \mathrm{~b}$ ). ${ }^{[30 \mathrm{~b}]}$ A related PQX ligand with only $5 \%$ of DIc1 was still significantly selective (70\% e.e.). This demonstrated a good control of the handedness of the helix by a small fraction of sergeants in these S\&S-type $\mathrm{PQX}$ ligands. Copolymers of the type poly-(DIPPh $\left.{ }^{50}-\mathrm{co}-\mathrm{DI} 1^{950}\right)$, i.e. with $95 \%$ of chiral units and $5 \%$ of phosphine-functionalized units, were investigated in different catalytic reactions. In addition to the above-mentioned hydrosilylation reaction, ${ }^{[30 \mathrm{~b}, 36]}$ they proved to be remarkably selective ligands for palladiumcatalyzed asymmetric Suzuki-Miyaura reactions ${ }^{[33,37]}$ (up to $98 \%$ e.e.) and arylative ring-opening of 1,4-epoxy-1,4dihydronaphthalene (up to $94 \%$ e.e.). ${ }^{[38]}$ In the silaborative cleavage of meso-methylenecyclopropanes ${ }^{[39]}$ (up to $97 \%$ e.e.), these PQXs ligands provided comparable or higher selectivities than known discrete chiral ligands. Changing the nature of the catalytically active monomer to a nitrogen-containing unit extended the scope of these PQX catalysts towards other asymmetric metal-catalyzed reactions ${ }^{[40]}$ or organocatalytic reactions. ${ }^{[41]}$

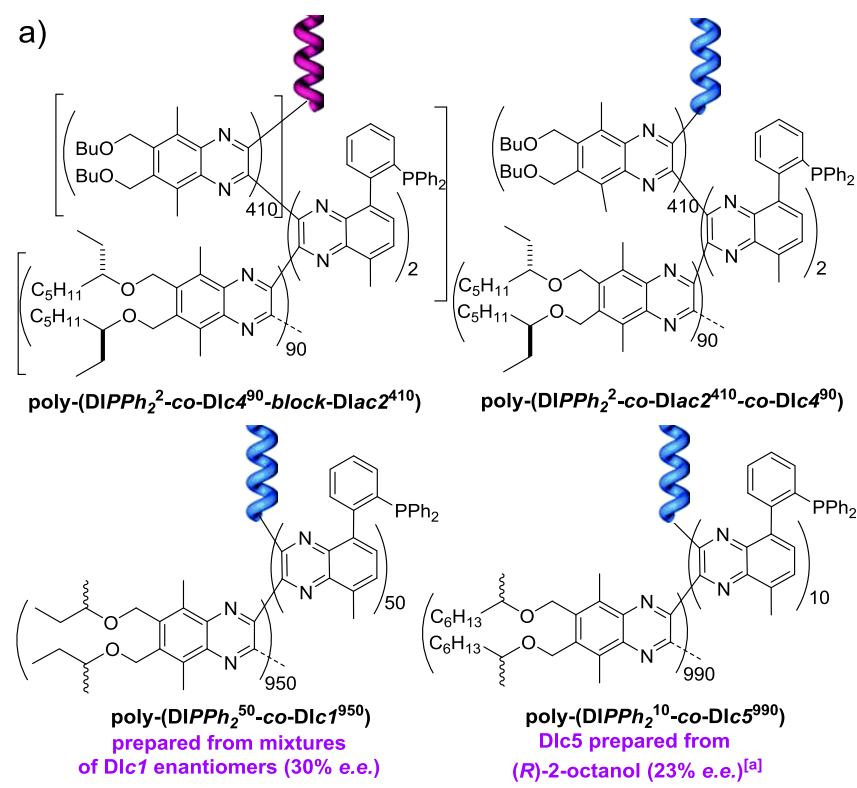

b)

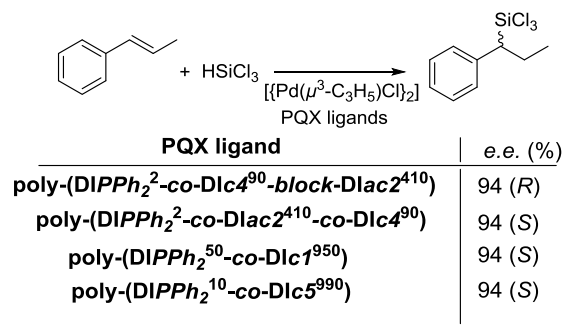

Figure 8 Asymmetric palladium-catalysed hydrosilylation of $\beta$-methylstyrene with S\&S- (a) and MR-type (b) PQX ligands. ${ }^{[42]}$ [a] DIc5 is a mixture of the $d, I$, and meso isomers in a ratio of $38.8: 15.8: 45.4$, respectively.

The influence of the chemical nature of sergeants on the optical purity of the resulting PQXs has been precisely probed with the aim of intensifying the extent of chirality amplification and the dynamic nature of PQX ligands. ${ }^{[43]}$ Notably, improved levels of chirality amplification were reported for DI sergeants having a (-)-menthol moiety located at the 6- and 7-positions (DIc2) or at the 5- and 8-positions (DIc3) of the quinoxaline ring (Figure 7). ${ }^{[35]}$ CD spectroscopy analyses revealed that polymers incorporating DIc2 or Dlc3 adopt opposite handedness even though these sergeants possess the same chiral moiety. The PQX ligand,

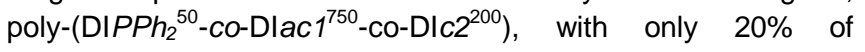
sergeants units, adopted a pure $(P)$-helical conformation and provided the $(S)$ hydrosilylation product with $95 \%$ e.e. Consistent with the $\mathrm{CD}$ data, the $(R)$-hydrosilylation product was the main enantiomer when the reaction was conducted with the PQX ligands containing DIc3 sergeants. Likewise, the enantioselectivity of the hydrosilylation reaction was precisely probed as a function of the fraction of DIc3 in these PQX ligands. Despite the fact that the helical backbone required $15 \%$ of DIc3 to adopt an absolute $(M)$-helical conformation, the selectivity was found to be maximal ( $90 \%$ e.e.) for $10 \%$ of DIc3 and then decreased for PQX ligands having higher ratios of DIc3. This intriguing effect was attributed to disorder of the helical structure induced by the sergeant and more precisely by the bulkiness of the chiral groups at the 5- and 8-positions. 


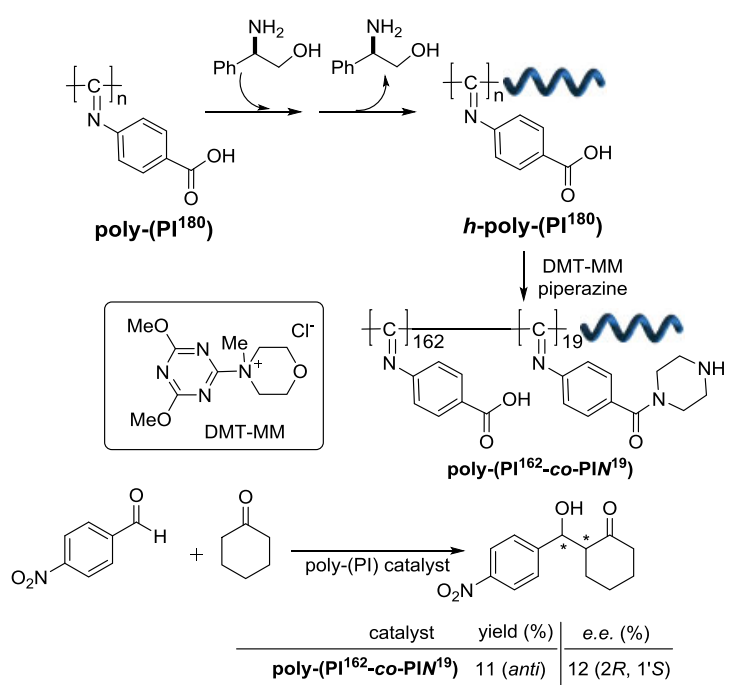

Figure 9. Asymmetric aldol reaction promoted by poly-(phenyl isocyanide)s with memorized helicity. ${ }^{[4]}$

Further work revealed that, for the same sergeant, the handedness of $P Q X$ helix can be controlled by its fraction and position in the copolymer. 100 mer-based random copolymers of Dlc4 and Dlac2 exhibited a single handed $(P)$-helix with $16 \%$ $20 \%$ of DIc4 and a pure $(M)$-helix with more than $60 \%$ of DIc4. ${ }^{[42 a]}$ Such an abnormal S\&S effect ${ }^{[45]}$ occurs when the preference of screw-sense induction of the sergeant depends on the nature of monomer units (sergeants or soldiers) in its immediate vicinity. This phenomenon was thus exploited to control the handedness of the PQX ligand by changing solely the sequence of the sergeants and soldiers. Two PQX ligands were prepared which both contained $18 \%$ of sergeants but distributed differently along the PQX main chain (Figure 8). The palladium complexes of the random $\mathrm{PQX}$ ligand, poly-(DIPPh${ }_{2}{ }^{2}$

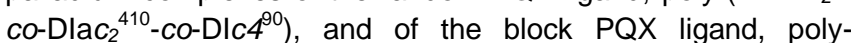
$\left(\mathrm{DIPPh}{ }_{2}{ }^{2}-\mathrm{co}-\mathrm{DI} c 4^{90}\right.$-block-Dlac2 $\left.{ }^{410}\right)$, furnished the $(S)$ and $(R)$ hydrosilylation product of $\beta$-methylstyrene, respectively, with the same selectivity (94\% e.e., Figure 8 ).

Chirality-amplification in PQX ligands was also achieved by means of non-racemic mixtures of enantiopure sergeants (diluted MR effect). A 1000 mer-based PQX ligand was found to adopt an almost absolute $(P)$-helical conformation even though the optical purity of DIc1 was as low as $30 \%$ e.e. (biased in favor of the $(R, R)$-enantiomer, Figure 8$) \cdot{ }^{[42 \mathrm{~b}]}$ As a result of the chirallyamplified nature of its scaffold, this $P Q X$ ligand promoted the palladium-catalysed hydrosilylation of $\beta$-methylstyrene with excellent enantioselectivity ( $94 \%$ e.e.). In addition, a monomer with 2-octyloxymethyl side chains, Dlc5, was prepared from $23 \%$ e.e. $(R)$-2-octanol, a readily available enantio-enriched mixture of alcohols, and used as a non-optically pure chiral inducer. The resulting $\mathrm{PQX}$ ligand, poly-(DIPPh$\left.{ }^{10}-\mathrm{co}-\mathrm{DI} c 5^{990}\right)$ exhibited excellent enantioselectivities in both the palladium-catalysed hydrosilylation of $\beta$-methylstryrene ( $94 \%$ e.e., Figure 8 ) and the Suzuki-Miyaura coupling between dimethoxyphosphinylsubstituted 1-naphthyl bromide and 1-naphthaleneboronic acid (93\% e.e.). These results highlighted the possibility of using a single chiral source with low e.e. value to generate highly selective helical catalysts.

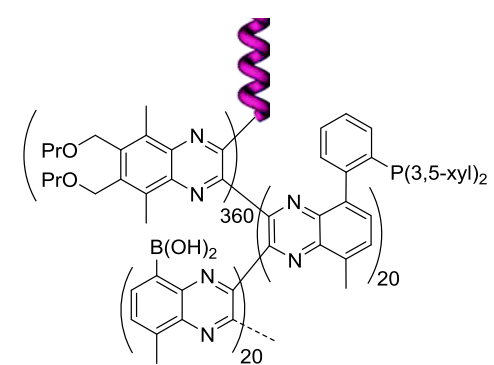

poly-(DIP(3,5-xyl) $2^{20}-$ co-Dlac3 $3^{20}-$ co-Dlac1 $\left.^{360}\right)$

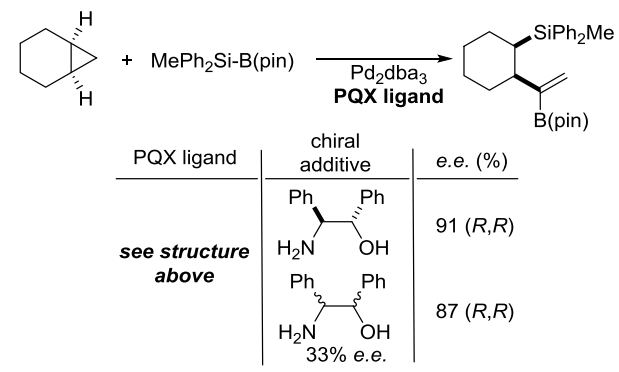

Figure 10. Asymmetric palladium-catalysed silaborative $C-C$ bond cleavage of meso-methylenecyclopropane with a combination of a PQX ligand and a chiral additive. ${ }^{[46]}$

\subsection{By addition of chiral additives}

Chiral additives, that are not part of the polymer main chain, can also be employed to impose a preferred handedness to covalent macromolecules. Removal of these additives may not be accompanied by racemization of the main chain at the condition that the helicity is kinetically locked (chiral memory effect). Yashima and co-workers demonstrated that such phenomena are operative for poly(4-carboxyphenyl isocyanide), poly-(PI), a racemic helical polymer that folds into a single-handed helix upon induction by an optically-active amine in water. ${ }^{[47]}$ After removal of the chiral inducer, $h$-poly- $\left(\mathrm{PI}^{180}\right)$ ( $h$ stands for memorized chiral helix) retains its helicity during a timescale that allows for its derivatization (Figure 9). The acidic groups of poly$\left(\left.\mathrm{P}\right|^{180}\right)$ served to introduce various amounts of piperazine $(\mathrm{PIN})$ functions at the periphery of the polymer. ${ }^{[44]}$ Importantly, no significant racemization of the helix occurred during the functionalization process. Poly- $\left(\mathrm{PI}^{162}-\mathrm{co}-\mathrm{PI} N^{19}\right)$, which contained $\approx 10 \%$ of piperazine units for activation of ketones, promoted the aldol reaction between cyclohexanone and 4-nitrobenzaldehyde with modest enantioselectivity ( $12 \%$ e.e., anti isomer). Yet, this example exploits the unique ability of some macromolecular helices to amplify and retain their inherent chirality in order to support catalytic centres that can be employed to produce optically-enriched compounds.

Condensation of chiral additives, such as diols, diamines and amino alcohols, to the boronic acid side chains of $P Q X$ polymers successfully induced a preferred handedness to the polymer main chain. ${ }^{[46]}$ A polymer endowed with both boronyl (5\%, Dlac3) and 2-[bis(3,5-dimethylphenyl)phosphino]phenyl pendants $\left(5 \%, \mathrm{DI} P(3,5-\mathrm{X} Y \mathrm{I})_{2}\right)$ was designed as a $\mathrm{PQX}$ ligand with a dynamic helical backbone (Figure 10). This PQX ligand and $(S, S)$-2-amino-1,2-diphenylethanol, the chiral inducer, proved to be the combination of choice for the palladium- 


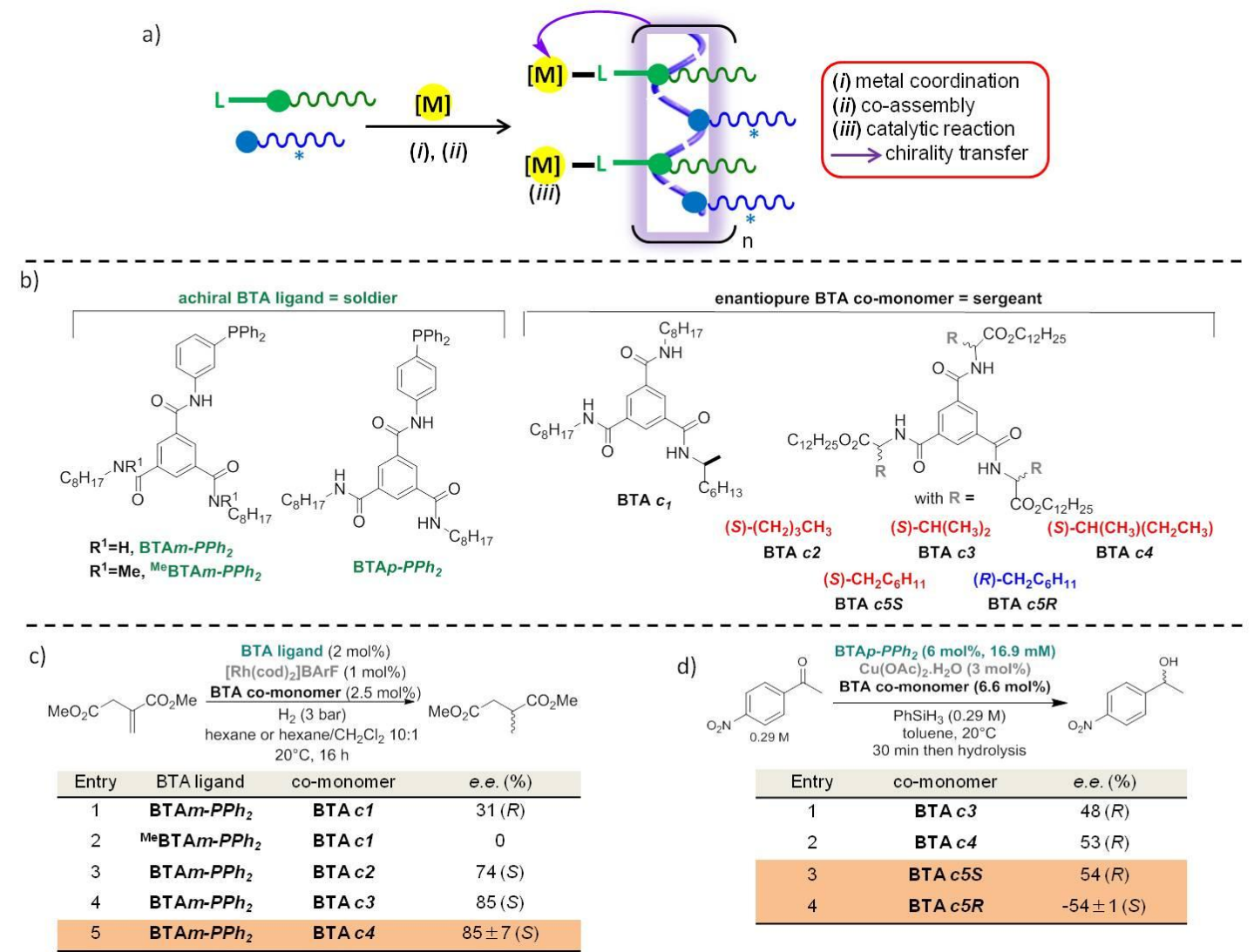

Figure 11. Asymmetric metal-catalysed reactions with supramolecular helical catalysts. a) Schematic representation of the preparation and mode of action of S\&S type non-covalent helical catalysts. b) Chemical structures of the BTA monomers. c) Results in the asymmetric rhodium-catalysed hydrogenation of dimethyl itaconate.$\left.^{[48]} \mathrm{d}\right)$ Results in the asymmetric copper-catalysed hydrosilylation of 4-nitroacetophenone. ${ }^{[49]}$

catalysed silaborative $\mathrm{C}-\mathrm{C}$ bond cleavage of mesomethylenecyclopropane ( $91 \%$ e.e.). Since this result was achieved with only 1 equivalent of chiral inducer per 19 achiral units (including 1 boronyl pendant), it means that chirality amplification was strongly operative in this PQX ligand. A similar experiment was performed with the same ligand but by adding a non-optically pure mixture of 2-amino-1,2-diphenylethanol enantiomers as chiral additives (33\% e.e., 10 equiv. per boronic pendants). The reaction also proceeded selectively albeit the e.e. was slightly lower $(87 \%$ e.e.). In these examples, the chiral additives constitute an alternative to enantiopure monomers for controlling and amplifying the main chain chirality of the helical catalyst.

\section{Chirally-amplified polymer catalysts}

supramolecular

Impressive efforts have been made in the control of the chirality of supramolecular polymers, notably by means of the S\&S and MR effects. ${ }^{[13 b, 18,27]}$ However, asymmetric catalytic reactions whose enantioselectivity is solely controlled by the helicity of the supramolecular polymers have only been reported by the groups of Liu $^{[50]}$ and Raynal ${ }^{[48-49,51]}$ and only the latter has investigated chirally-amplified assemblies in that context.

The ability of benzene-1,3,5-tricarboxamide (BTA) molecules ${ }^{[52]}$ to predictably assemble into robust threefold hydrogen-bonded helical assemblies in apolar solvents was exploited to control the handedness of supramolecular helical BTA catalysts (Figure 11a). The combination of the achiral monomer BTAm-PPh (Figure 11b) and the enantiopure but phosphorus-free BTA monomer, BTAc1, in a 1:1.25 ratio, proved to be slightly selective for the rhodium-catalysed hydrogenation of dimethyl itaconate $(31 \%$ e.e., Figure $11 \mathrm{c}) .{ }^{[48 \mathrm{a}]}$ A control experiment, performed with an analogue of BTAm- $P P h_{2}$ that is unable to selfassemble ( ${ }^{\mathrm{Me}} \mathrm{BTAm}-P P h_{2}$ ), showed no selectivity under the same conditions which demonstrates that the observed enantioselectivity, albeit modest, stems from the helical nature of the co-assembly formed between BTAm-PPh $h_{2}$ and BTAc1. The role of BTA $c 1$ in these co-assemblies is thought to be similar to the role of a sergeant in the S\&S-type covalent helical catalysts mentioned above.

BTA derived from $\alpha$-amino esters ${ }^{[53]}$ were found to be far more efficient sergeants than BTAc1. The selectivity was remarkably increased for the same catalytic reaction when BTAm- $P P h_{2}$ was mixed with 1.25 equivalent of the BTAs derived from Norleucine (BTA c2, $74 \%$ e.e.), Valine (BTA c3, $85 \%$ e.e.) or Isoleucine (BTA c4, $85 \%$ e.e.). ${ }^{[48 \mathrm{~b}]}$ Likewise, the amount of BTAc4 in the catalytic mixture was varied (Figure 12a). For mixtures with a minority of sergeants, the selectivity of the reaction increased non linearly and reached a plateau corresponding to the optimal selectivity for the mixture with ca. $20 \%$ of BTA c4. It means that one molecule of sergeant is sufficient to induce 
a)

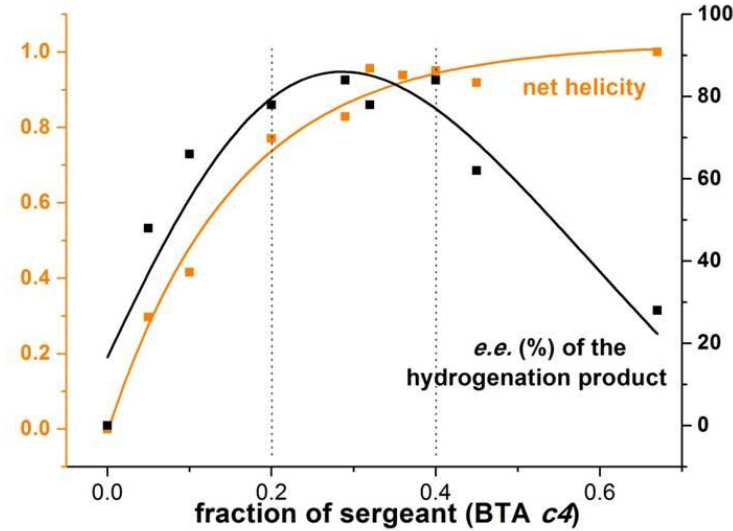

b)

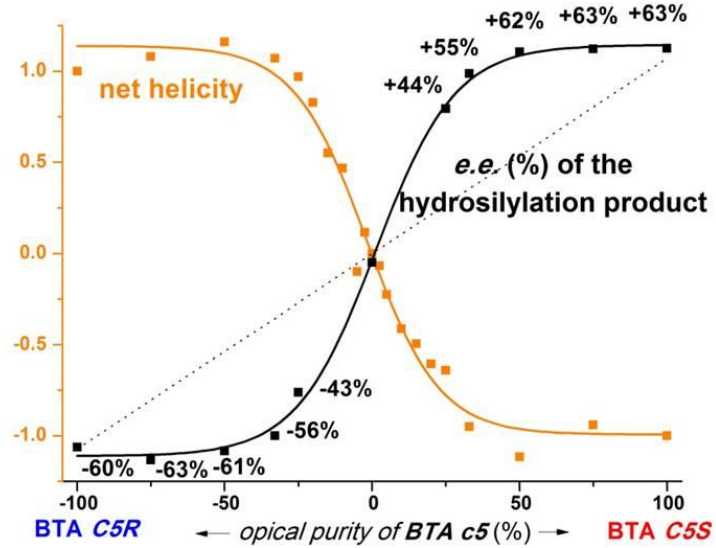

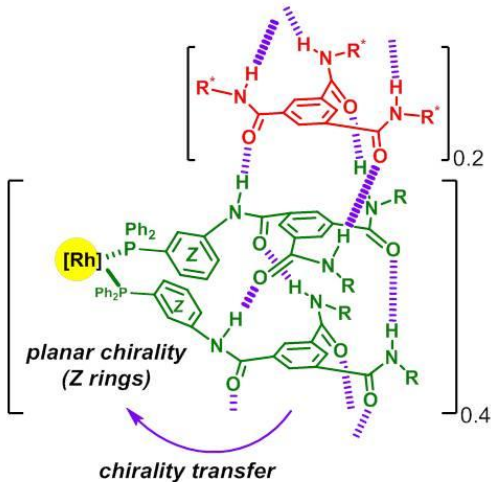

chirality transfer

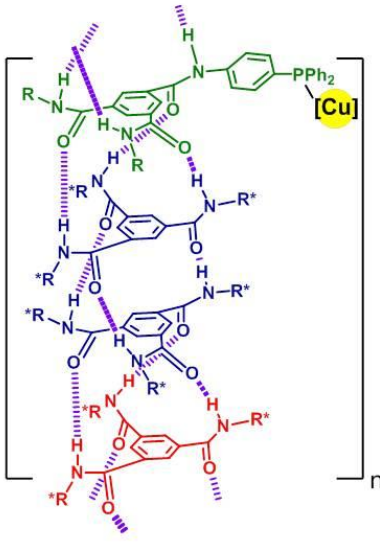

Figure 12. S\&S type (a) and MR type (b) supramolecular helical catalysts and schematic representation of the respective structures. Plot of the selectivity and net helicity as a function of the amount of BTA $c 4$ in the catalytic mixture (a) or of the optical purity of BTA $c 5$ in the catalytic mixture (b).

a chiral environment to four achiral ligands (or two rhodium catalytic centres). A series of spectroscopic and scattering analyses confirmed the formation of a chirally-amplified coassembly with a single BTA molecule in the cross-section for this mixture. The major enantiomer and the selectivity of the catalytic reaction are thus related to the handedness and the net helicity of the co-assemblies, respectively. It is worth mentioning here that the chirally-amplified $P Q X$ asymmetric catalysts mentioned in the preceding section require the use of an achiral monomer acting as a spacer between the catalytic sites and thus the amount of sergeant in these systems is actually larger than the catalytic loading. The supramolecular asymmetric catalyst built on the BTA scaffold thus constituted the first example in which a substoichiometric amount of a chiral inducer relative to the achiral ligand can be used without eroding the stereoselectivity of the catalytic reaction. Conversely, the selectivity noticeably decreased for mixtures containing a higher content of enantiopure co-monomer $(\geq 60 \%)$. However, CD analyses showed that the helices were still single-handed which discarded the occurrence of an abnormal S\&S effect as mentioned above for $P Q X$ ligands. We postulated that this erosion of selectivity was rather due to a change in the coordination mode of the supramolecular ligand: from a selective chelating ligand in low-content BTA c4 mixtures (see a representation in Figure 12a) to poorly selective bridging ligand in high-content sergeant mixtures. This change in the coordination mode of the ligand is a consequence of the dynamic nature of this class of hydrogen-bonded catalysts.

Later, mixtures of related BTA monomers were evaluated in the copper-catalyzed hydrosilylation of 4-nitroacetophenone. ${ }^{[49]}$ Here, the combination of BTAp-PPh $h_{2}$ and the enantiopure BTA derived from cyclohexylalanine, BTA c5 (1.1 equiv.), displayed the highest selectivity $(54 \%$ e.e. at room temperature, Figure 11c). In-depth characterization of this catalytic mixture revealed that co-assemblies were one-dimensional, very long $\left(\mathrm{DP}_{\mathrm{n}} \approx 250\right)$ stacks with a single molecule in the cross-section and contained approximately two BTAp-PPh $h_{2}$ molecules for one BTA $c 5^{[51]}$ The selectivity was then recorded as a function of the optical purity of BTA c5 (Figure 12b) and interestingly an almost optimal selectivity was obtained for a 2:1 mixture of enantiomers $33 \%$ e.e.). The chiroptical properties of these mixtures were assessed by circular dichroism. The curve describing the helicity of the BTA co-assemblies as a function of the optical purity of the sergeant was similar to the one obtained for the selectivity (Figure 12b). This demonstrates that the chirality amplification effect observed in the catalytic experiments stems from the chirally-amplified nature of the helical scaffold of the catalyst. The dynamic nature of the assemblies was further exploited to switch and tune the selectivity of consecutive catalytic reactions (vide infra). 
a) ref. $41 \mathrm{~b}$<smiles>CCC(c1ccccc1)c1ccccc1</smiles>
$90 \%$ yield 1,1,2-TCE/toluene(3:1)<smiles>C[AsH2]=CC=Cc1ccccc1</smiles>

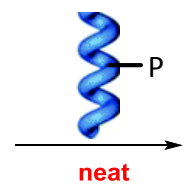<smiles>CCC(c1ccccc1)[Si](Cl)(Cl)Cl</smiles>
95\% e.e. poly-(DIPPh2 ${ }^{10}-$ co-DIc $\left.5^{990}\right)^{[\mathrm{a}]}$

$\left[\left\{\mathrm{Pd}\left(\mu^{3}-\mathrm{C}_{3} \mathrm{H}_{5}\right) \mathrm{Cl}\right\}_{2}\right]$

$89 \%$ yield $94 \%$ e.e.

b) ref. 35<smiles>CCC(c1ccccc1)c1ccccc1</smiles>

$88 \%$ yield $94 \%$ e.e.

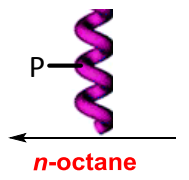

poly-(DIPPh2 ${ }^{10}$-co-Dlc4 ${ }^{990}$ ) $\left[\left\{\mathrm{Pd}\left(\mu^{3}-\mathrm{C}_{3} \mathrm{H}_{5}\right) \mathrm{Cl}\right\}_{2}\right]$

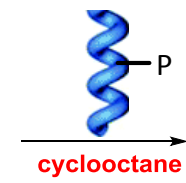

(1)

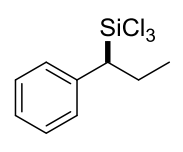

$89 \%$ yield $90 \%$ e.e.

c) ref. $53 a$<smiles>COc1ccc2ccccc2c1-c1ccc(C)c2ccccc12</smiles>

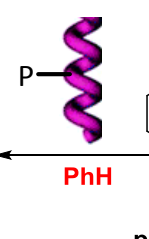

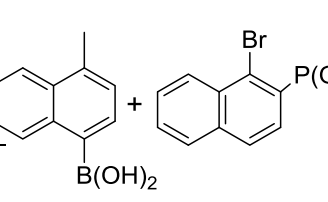

poly-(DIPPh2 ${ }^{10}$-co-Dlac $1^{600}-c 0-D I c 4^{400}$ ) d) ref. $36 \mathrm{a}$ $91 \%$ e.e. $\left[\mathrm{Pd}(\mathrm{dba})_{2}\right]$<smiles>COc1ccc(C(C)(F)F)cc1</smiles>

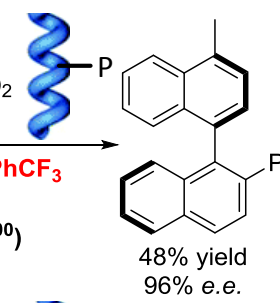
$\mathrm{P}(\mathrm{O})(\mathrm{OMe})_{2}$ $48 \%$ yield<smiles>COC(=O)c1ccc2ccccc2c1-c1cccc2cc([18O])ccc12</smiles>

Figure 13 Selectivity-switchable PQX ligands triggered by the solvent. (a] DIc5 is a mixture of the $d$, I, and meso isomers in a ratio of $38.8: 15.8: 45.4$, respectively (see also Fig. 8a).

\section{Switchable catalysis with chirally- amplified polymer catalysts}

\subsection{Enantiodivergent catalysis promoted by solvent nature}

As a consequence of the conformational flexibility of their main chain, a range of helical macromolecules undergo a reversible switch of their handedness upon activation by various chemical or photophysical stimuli. ${ }^{[13]}$ The helical backbone of PQXs is particularly prone to stereochemical inversion since bidirectional induction had been achieved by changing the position of the chiral moiety on the quinaxoline ring (Figure 7$)^{[35]}$ by modifying the structure of the soldier ${ }^{[42 a]}$ or the sergeant, ${ }^{[43]}$ by controlling the sequence of the monomers (Figure $8 \mathrm{a}),{ }^{[42 a]}$ or by the solvent. ${ }^{[30 b, 33,35-37,39-41,43,54]}$ The use of the solvent effect ${ }^{[55]}$ to switch the main helical sense of PQX-based catalysts offers the possibility to produce both enantiomers of a reaction starting from the same chiral catalyst. Achieving enantiodivergency in a rational and predictable manner is a current challenge in stereoselective catalytic reactions.

Based on the initial finding that PQXs bearing chiral $(R)-2$ butoxymethyl side chains adopt pure but opposite screw senses in $\mathrm{CHCl}_{3}$ and 1,1,2-trichloroethane (TCE), ${ }^{[54 \mathrm{~b}]}$ switchable PQX ligands were prepared by copolymerization of DIPPh $h_{2}$ and DIc1. Helical inversion to $(M)$-helix occurred upon heating a solution of the as synthesized $(P)$-helical ligands in TCE/THF or TCE/toluene. Full inversion of the handedness of the PQX ligand resulted in the highly enantioselective production of both enantiomers in a range of catalytic reactions. ${ }^{[30 \mathrm{~b}, 33}$ 37b, 39-41] Interestingly, the MR-type PQX ligand mentioned in Figure 8a with a highly chirally-amplified helical backbone also exhibited inversion of the selectivity in these solvent mixtures (Figure 13a). ${ }^{[42 b]}$

The need of halogenated solvents somewhat impedes the general applicability of the PQX ligand, notably for metalcatalyzed cross-coupling reactions, and thus PQXs which can invert their handedness in other solvents have been developed. An important element of design is the nature of the chiral monomer. Poly-(Dlc1 $\left.{ }^{100}\right)$ showed no inversion of its helicity in alkanes while poly-(DIC4 $\left.{ }^{100}\right)$ adopted a $(P)$ - or $(M)$-helix in cyclooctane and $n$-octane, respectively. ${ }^{[36]}$ Consequently, the $\mathrm{PQX}$ ligand incorporating $99 \%$ of DIc4 and $1 \%$ of $\mathrm{DIPPh}_{2}$ yielded both enantiomers in the hydrosilylation of styrene depending on the nature of the alkane solvent selected to conduct the reaction (Figure 13b). When considering S\&S-type PQXs, the selection of the soldier was also found to be crucial 


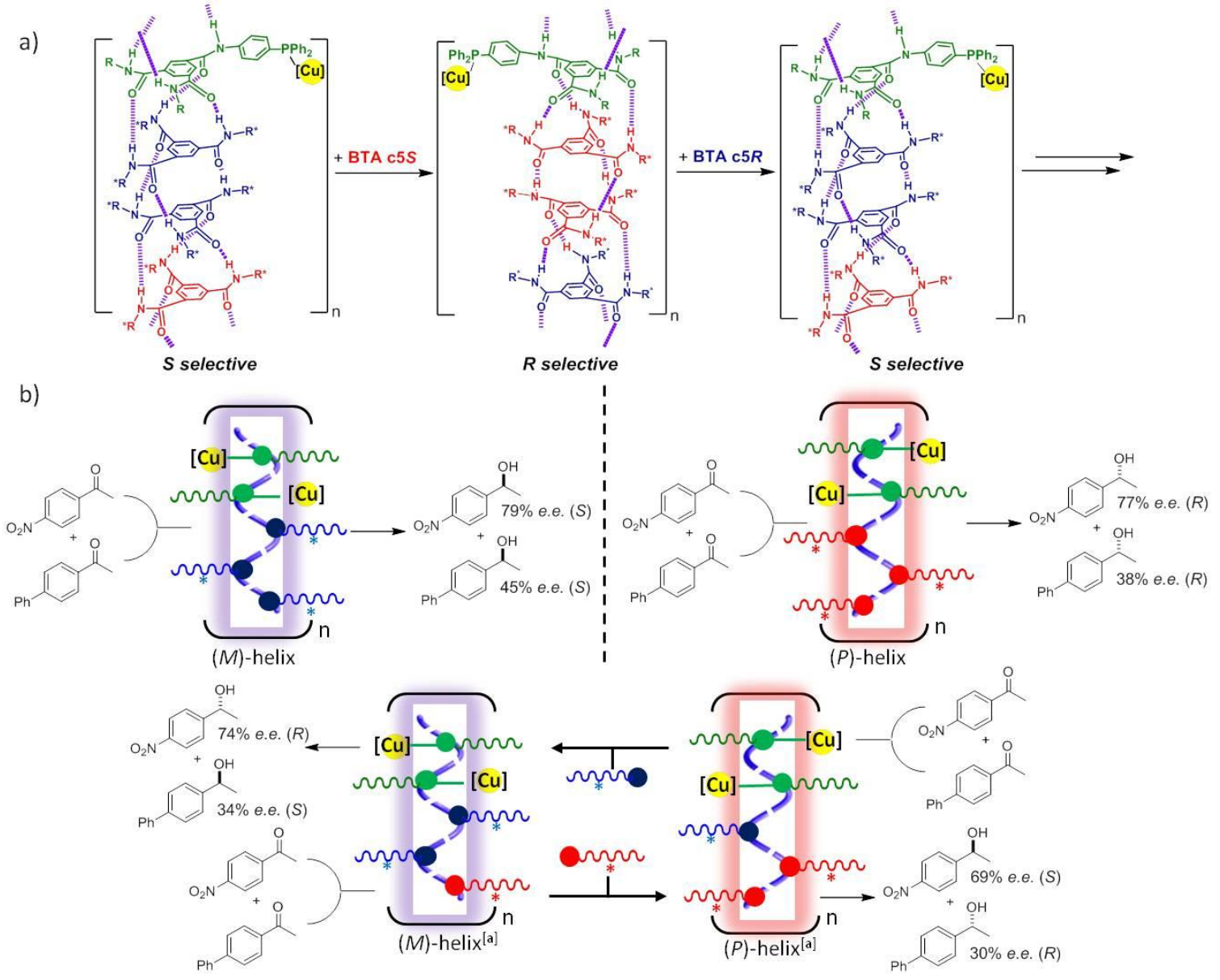

Figure 14 Selectivity-switchable supramolecular helical catalyst. a) Reversal of selectivity by means of addition of BTA c5. b) Real-time control of the selectivity in the consecutive hydrosilylation of a mixture of two substrates. ${ }^{[49]}$ [a] A $60 \%$ e.e. scalemic mixture of BTA c5 was employed.

for the observation of the solvent-induced reversal of selectivity. Poly-(DIc4 ${ }^{5}$-co-Dlac2 $\left.{ }^{100}\right)$ adopted exclusively a $(P)$-helical conformation in various aromatic solvents. Conversely, poly$\left(\mathrm{Dlc} 4^{5}-\mathrm{co}\right.$-Dlac1 $\left.{ }^{100}\right)$, which contains the same sergeants but a different soldier, exhibited opposite handedness in benzene $((M)$-helix $)$ and $\mathrm{PhCF}_{3}\left((P)\right.$-helix). ${ }^{[54 a]}$ This result was exploited to design a PQX ligand mainly composed of Dlc4 and Dlac1 and with only $1 \%$ of $D I P P h_{2}$ in order to maintain the solvent effect. This S\&S-type PQX ligand, poly-(DIPPh ${ }^{10}$-co-Dlac ${ }^{600}$-co$\mathrm{DIc} 4^{400}$ ), promoted the palladium-catalyzed Suzuki-Miyaura shown in Figure 13c with high and opposite enantioselectivities in benzene (91\% e.e., $(R)$-product) and $\mathrm{PhCF}_{3}(96 \%$ e.e., $(S)$ product).

Such a stereochemical inversion of the catalytic outcome by the solvent is particularly valuable when the chiral catalyst is derived from a naturally occurring chiral compound. The PQX homopolymer derived from L-lactic acid, poly-(DIc $\left.6^{40}\right)$, was found to be right-handed in MTBE and left-handed in a range of other ether solvents. ${ }^{[37 a]}$ The PQX ligand incorporating $95 \%$ of DIc6, poly-(DIPPh $\left.{ }_{2}^{50}-c o-D I c 6^{1000}\right)$, adopted almost absolute $(M)$ - and $(P)$-helical structures in 1,2-DME and MTBE, respectively, and thus furnished both enantiomers in the Suzuki-Miyaura coupling shown in Figure 13d when the reaction was performed in these solvents.

\subsection{Enantiodivergent catalysis promoted by the addition of a chiral monomer}

Inverting the enantioselectivity of a single catalyst involved in consecutive reactions can afford selecting a single enantiomer in one pot stereoselective cascade reactions ${ }^{[56]}$ or controlling the tacticity ${ }^{[57]}$ of stereoblock copolymers. With these far-reaching objectives in mind, we designed a supramolecular helical catalyst whose selectivity can be rationally controlled in real time by simple addition of a chiral monomer. This concept relies on the possibility of switching the handedness, and thus the selectivity, of the chirally-amplified BTA helical ligand by changing the nature of majority sergeant enantiomer (Figure 14a). A series of catalytic experiments demonstrated that the stereochemical preference of the BTA catalyst can indeed be switched in ca. 5 seconds upon adding an excess of an enantiomer in the co-assemblies. It allows the selectivity of the catalyst to be switched during a reaction. In particular, controlling the handedness of the helical catalyst, $(P)$ only, $(M)$ only, $(P)$ then $(M)$, and $(M)$ then $(P)$, during the hydrosilylation of a mixture of two substrates displaying different reactivity generates all the combinations of the product enantiomers, i.e. $(R) ;(R),(S) ;(S),(R) ;(\mathrm{S})$ and $(\mathrm{S}) ;(\mathrm{R})$, respectively (Figure 14b). The chirally-amplified nature of the helix and its rapid inversion 
a)

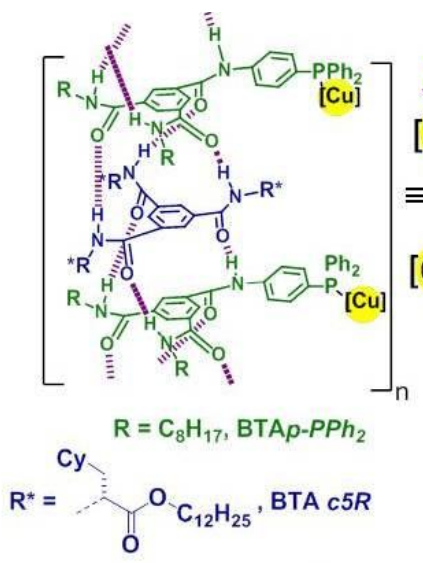

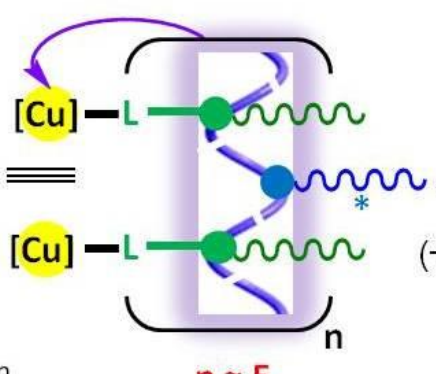

$\mathrm{n} \approx 5$

enantioselective

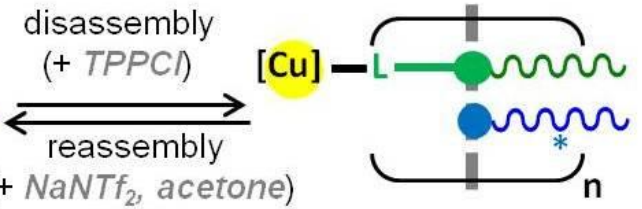

$\mathrm{NaCl} \downarrow$
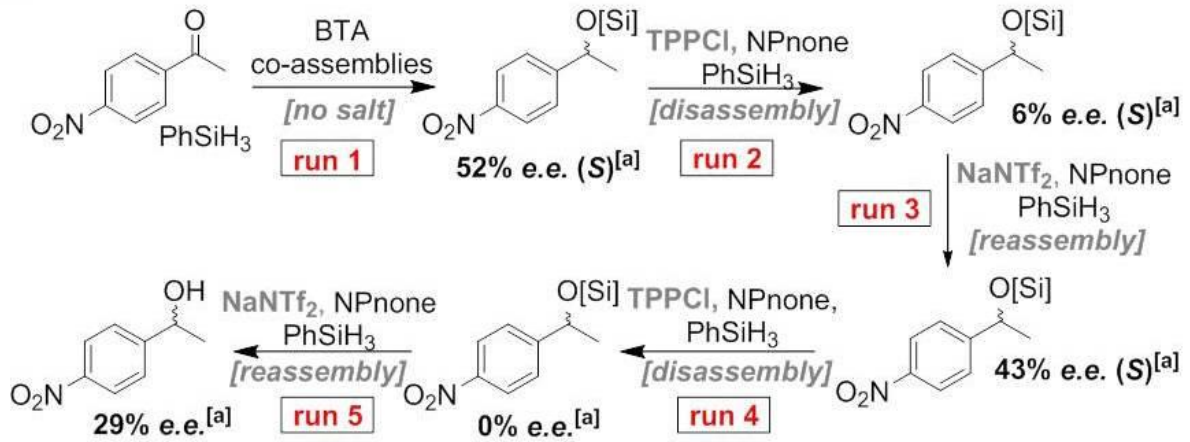

Figure 15 Selectivity-tunable supramolecular helical catalyst. a) Schematic representation of the present concept. Supramolecular helices are shortened and lengthened reversibly by means of an appropriate combination of salts. b) Modulation of the enantioselectivity of the supramolecular catalyst involved in the hydrosilylation of several equivalents of 4-nitroacetophenone added sequentially in the reaction mixture. [a] Enantioselectivity of the run after hydrolysis.

cause no significant dwindling of the selectivity when the enantiomeric state of the catalyst is repeatedly changed during the course of the catalytic reaction.

\subsection{Modulation of selectivity by reversible assembly of supramolecular helices}

The hydrogen-bonded network connecting the monomer units of a supramolecular polymer is particularly sensitive to the environment. Whilst their dynamic nature hampers the preparation of BTA catalysts with a monodispersed size, anions can be used to reduce their average length without affecting their structure. We anticipated that the selectivity provided by the helical co-assemblies composed of BTAp-PPh $h_{2}$ and BTA c5 can be tuned to a certain extent by changing the average length of the supramolecular helices. We indeed found that the enantioselectivity gradually decreased as a function of the amount of chloride anions present during the hydrosilylation of 4-nitroacetophenone: from $44 \%$ e.e. ( 0.3 equiv. relative to BTAp$P P h_{2}$ ) to $0 \%$ e.e (1.0 equiv.). The chloride anions could then be removed through a salt metathesis reaction under the form of sodium chloride (see a schematic representation of the concept in Figure 15a). Adding $\mathrm{NaNTf}_{2}$ to the catalytic mixture containing chloride anions led to an increase of the selectivity and this combination of salts allows a reversible switch of the enantioselectivity in four successive reactions (Figure 15b). Thorough characterization of the co-assemblies present during the first three runs corroborated the relation between the average length of the helices, the chiral environment of the ligand and the selectivity of the catalytic reaction. It was also established that a critical length in the range of ca. ten monomer units was required to locate most of the copper centres in a chiral environment suitable for asymmetric induction. This constitutes a robust design for the development of future catalysts based on these dynamic helical nanostructures.

\section{Summary and Outlook}

Up to now, chirality amplification in the context of asymmetric catalysis has mostly been associated to the increase of the apparent optical purity of a mixture of enantiopure catalysts (positive NLE effects) or to the enhanced selectivity promoted by auto-induction processes. These effects likely arise from intricate aggregation phenomena involving several molecules involved in the catalytic reaction. Conversely, chirality amplification is a ubiquitous and well characterized phenomenon in polymer science which occurs when a helical polymer adopts a single handed conformation even through it is not solely constituted of enantiopure monomers. However, it was only ten years ago that helical covalent polymers, with intrinsically achira catalytic centres embedded in a chirally-amplified polymer main chain, was found to promote asymmetric reactions with a significant level of enantioinduction. The modest selectivity reported for helical catalysts developed prior to 2009 likely resulted from the poor enantiodifferentiating environment provided by the helix and the limited stability of the helical conformation. Today, these two crucial factors remain challenging to predict when it comes to envisage a new type of 
helical catalyst. In this context, poly(quinoxaline-2,3-diyl)s proved to be the most versatile backbone to date since it provided a suitable chiral environment for achiral $\mathrm{Pd}$ and $\mathrm{Cu}$ complexes and for 4-aminopyridine moieties which in turn promoted different types of asymmetric reactions with satisfactory levels of enantioselectivity. Efficient chirality transfer between the stereogenic centres (central chirality) located in the sergeant side chain, the helical backbone (helical chirality) and the phenyl group (axial chirality) supporting the catalytic centre is likely at the origin of the high degree of enantioinduction achieved with these helical catalysts. Another benefit of this class polymer relies on the conformationally flexible character of their helical main chain which allows to switch the enantioselectivity with the same chiral catalyst by simply changing the nature of the solvent used to conduct the catalytic reaction. In the last six years, good levels of enantioselection have also been achieved by supporting achiral rhodium and copper catalytic centres at the periphery of supramolecular helices. Here, the catalyst composition is highly tunable since it is prepared by in situ co-assembly between phosphinefunctionalized benzene-1,3,5-tricarboxamide (BTA) units and enantiopure BTA monomers. The dynamic nature of the hydrogen-bonded network connecting the different units allows to tune the selectivity in real time during consecutive reactions. Also, thanks to good chirality amplification properties of the BTA scaffold, the amount of sergeants can be decreased below the catalytic loading without impairing the selectivity. Finally, the rational design of these catalysts is made possible by the direct relationship between the sergeant chirality, the supramolecular helix handedness and the enantioselectivity of the catalytic reaction.

Overall, one can consider that helical catalysts built on a chirallyamplified backbone are at their early stage of development. For example, the scope of organometallic reactions promoted by these catalysts is limited and extension of this scope will require a better control of the coordination mode of the ligands located at the periphery of the helices which is a challenge to date. Ongoing effort must be devoted to enhance the dynamic features of these helical catalysts as well as to develop new properties such as cooperativity between the catalytic sites. A single catalyst combining all these properties will allow applications that are out of reach of conventional molecular catalysts. As asymmetric induction and amplification phenomena might have been involved in prebiotic chemistry, ${ }^{[21 b]}$ studying such helical catalysts built on highly chirally-amplified scaffolds or on related spontaneous mirror symmetry broken assemblies may also serve as model systems for understanding the initial chemical events that have led to homochirality on Earth. We hope that the present review will foster further work towards these directions.

\section{Acknowledgements}

This work was supported by the China Scholarship Council (CSC, PhD grant of Y. L.) and by the French Agence Nationale de la Recherche (project ANR-17-CE07-0002 AbsoluCat).

\section{Conflict of Interest}

The authors declare no conflict of interest.

\section{Keywords:}

chirality amplification - asymmetric catalysis · macromolecular helices supramolecular helices · switchable catalysis

[1] a) H. B. Kagan, T. P. Dang, J. Am. Chem. Soc. 1972, 94, 6429-6433; b) A. Miyashita, A. Yasuda, H. Takaya, K. Toriumi, T. Ito, T. Souchi, R. Noyori, J. Am. Chem. Soc. 1980, 102, 7932-7934; c) H. C. Kolb, M. S Vannieuwenhze, K. B. Sharpless, Chem. Rev. 1994, 94, 2483-2547; d) R. Noyori, Angew. Chem. Int. Ed. 2002, 41, 2008-2022; e) B. M. Trost Proc. Natl. Acad. Sci. U. S. A. 2004, 101, 5348-5355.

[2] a) B. List, R. A. Lerner, C. F. Barbas III, J. Am. Chem. Soc. 2000, 122 2395-2396; b) K. A. Ahrendt, C. J. Borths, D. W. C. MacMillan, J. Am Chem. Soc. 2000, 122, 4243-4244; c) A. Dondoni, A. Massi, Angew. Chem. Int. Ed. 2008, 47, 4638-4660.

[3] a) M. Avalos, R. Babiano, P. Cintas, J. L. Jimenez, J. C. Palacios, L. D. Barron, Chem. Rev. 1998, 98, 2391-2404; b) B. L. Feringa, R. A. van Delden, Angew. Chem. Int. Ed. 1999, 38, 3419-3438.

[4] For the Horeau principle and its implentation in asymmetric catalysis see the following reference and references therein: J. Merad, P. Borkar, F. Caijo, J. M. Pons, J. L. Parrain, O. Chuzel, C. Bressy, Angew. Chem. Int. Ed. 2017, 56, 16052-16056.

[5] a) R. Noyori, M. Kitamura, Angew. Chem. Int. Ed. Engl. 1991, 30, 4969; b) D. Guillaneux, S. H. Zhao, O. Samuel, D. Rainford, H. B. Kagan, J. Am. Chem. Soc. 1994, 116, 9430-9439; c) T. Satyanarayana, S. Abraham, H. B. Kagan, Angew. Chem. Int. Ed. 2009, 48, 456-494. For an example in which a scalemic mixture of enantiopure ligands provided a higher selectivity than the enantiopure ligand see: d) $Y$ Geiger, T. Achard, A. Maisse-François, S. Bellemin-Laponnaz, ChemRxiv, doi.org/10.26434/chemrxiv.8108735.v1.

[6] M. Klussmann, H. Iwamura, S. P. Mathew, D. H. Wells, U. Pandya, A Armstrong, D. G. Blackmond, Nature 2006, 441, 621-623.

[7] H. B. Kagan, Adv. Synth. Catal. 2001, 343, 227-233

[8] a) J. W. Faller, A. R. Lavoie, J. Parr, Chem. Rev. 2003, 103, 33453367; b) K. Mikami, M. Yamanaka, Chem. Rev. 2003, 103, 3369-3400 c) K. Mikami, Y. Yusa, T. Korenaga, Org. Lett. 2002, 4, 1643-1645.

[9] a) K. Soai, T. Shibata, H. Morioka, K. Choji, Nature 1995, 378, 767-768; b) K. Soai, T. Kawasaki, A. Matsumoto, Acc. Chem. Res. 2014, 47, 3643-3654

[10] A. Matsumoto, T. Abe, A. Hara, T. Tobita, T. Sasagawa, T. Kawasaki, K. Soai, Angew. Chem. Int. Ed. 2015, 15218-15221.

[11] a) I. Weissbuch, M. Lahav, Chem. Rev. 2011, 111, 3236-3267; b) J. M. Ribó, C. Blanco, J. Crusats, Z. El-Hachemi, D. Hochberg, A. Moyano, Chem. Eur. J. 2014, 20, 17250-17271.

[12] a) M. M. Green, J. W. Park, T. Sato, A. Teramoto, S. Lifson, R. L. B. Selinger, J. V. Selinger, Angew. Chem. Int. Ed. 1999, 38, 3139-3154; b) P. Pino, F. Ciardelli, G. Montagno., O. Pieroni, J. Polym. Sci. Polym. Lett. 1967, 5, 307-311; c) C. Carlini, F. Ciardelli, P. Pino, Makromol. Chem. 1968, 119, 244-248.

[13] a) E. Yashima, K. Maeda, H. lida, Y. Furusho, K. Nagai, Chem. Rev 2009, 109, 6102-6211; b) E. Yashima, N. Ousaka, D. Taura, K Shimomura, T. Ikai, K. Maeda, Chem. Rev. 2016, 116, 13752-13990.

[14] M. M. Green, M. P. Reidy, R. J. Johnson, G. Darling, D. J. Oleary, G. Willson, J. Am. Chem. Soc. 1989, 111, 6452-6454.

[15] M. M. Green, B. A. Garetz, B. Munoz, H. P. Chang, S. Hoke, R. G. Cooks, J. Am. Chem. Soc. 1995, 117, 4181-4182.

[16] a) Y. Okamoto, K. Suzuki, K. Ohta, K. Hatada, H. Yuki, J. Am. Chem. Soc. 1979, 101, 4763-4765; b) T. Nakano, Y. Okamoto, Chem. Rev. 2001, 101, 4013-4038.

[17] M. Suginome, T. Yamamoto, Y. Nagata, J. Synth. Org. Chem. Jpn 2015, 73, 1141-1155.

[18] M. H. Liu, L. Zhang, T. Y. Wang, Chem. Rev. 2015, 115, 7304-7397.

[19] Asymmetric reactions performed with helical PQX catalysts dissolved in chiral solvents, including scalemic mixtures, have been disclosed after the submission of this manuscrpt: Y. Nagata, R. Takeda, M. Suginome, ACS Cent. Sci. 2019, 5, 1235-1240.

[20] For a rare example of helix sense-selectrive supramolecular polymerization see: W. Zhang, W. S. Jin, T. Fukushima, T. Mori, T. Aida, J. Am. Chem. Soc. 2015, 137, 13792-13795. 
[21] a) E. A. C. Davie, S. M. Mennen, Y. Xu, S. J. Miller, Chem. Rev. 2007, 107, 5759-5812; b) D. R. Kelly, A. Meek, S. M. Roberts, Chem Commun. 2004, 2021-2022.

[22] A. J. Boersma, R. P. Megens, B. L. Feringa, G. Roelfes, Chem. Soc. Rev. 2010, 39, 2083-2092.

[23] L. X. Wang, J. F. Xiang, Y. L. Tang, Adv. Synth. Catal. 2015, 357, 1320.

[24] a) Q. S. Hu, W. S. Huang, D. Vitharana, X. F. Zheng, L. Pu, J. Am Chem. Soc. 1997, 119, 12454-12464; b) E. Yashima, Y. Maeda, Y. Okamoto, Polym. J. 1999, 31, 1033-1036; c) Y. Furusho, T. Maeda, T. Takeuchi, N. Makino, T. Takata, Chem. Lett. 2001, 1020-1021; d) D. Y. Zhang, C. L. Ren, W. T. Yang, J. P. Deng, Macromol. Rapid. Commun. 2012, 33, 652-657; e) H. lida, S. Iwahana, T. Mizoguchi, E. Yashima, J Am. Chem. Soc. 2012, 134, 15103-15113; f) E. Huerta, B. van Genabeek, B. A. G. Lamers, M. M. E. Koenigs, E. W. Meijer, A. R. A Palmans, Chem. Eur. J. 2015, 21, 3682-3690; g) N. Singh, M. Kumar, J. F. Miravet, R. V. Ulijn, B. Escuder, Chem. Eur. J. 2017, 23, 981-993; h) L. Zhou, B. F. Chu, X. Y. Xu, L. Xu, N. Liu, Z. Q. Wu, ACS Macro Lett. 2017, 6, 824-829; i) S. Bhowmick, L. Zhang, G. H. Ouyang, M. H. Liu Acs Omega 2018, 3, 8329-8336.

[25] a) C. T. Yeung, H. L. Yeung, C. S. Tsang, W. Y. Wong, H. L. Kwong, Chem Commun 2007, 5203-5205; b) T. Hasegawa, Y. Furusho, H. Katagiri, E. Yashima, Angew. Chem. Int. Ed. 2007, 46, 5885-5888; c) G. Maayan, M. D. Ward, K. Kirshenbaum, Proc. Natl. Acad. Sci. USA 2009, 106, 13679-13684; d) N. Ousaka, T. Yamaguchi, E. Yashima, Chem. Lett. 2014, 43, 512-514; e) B. A. F. Le Bailly, L. Byrne, J. Clayden, Angew. Chem. Int. Ed. 2016, 55, 2132-2136; f) D. Taura, S Hioki, J. Tanabe, N. Ousaka, E. Yashima, ACS Catal. 2016, 6, 46854689; g) D. Becart, V. Diemer, A. Salaun, M. Oiarbide, Y. R. Nelli, B. Kauffmann, L. Fischer, C. Palomo, G. Guichard, J. Am. Chem. Soc. 2017, 139, 12524-12532.

[26] R. P. Megens, G. Roelfes, Chem. Eur. J. 2011, 17, 8514-8523.

[27] A. R. A. Palmans, E. W. Meijer, Angew. Chem. Int. Ed. 2007, 46, 89488968.

[28] M. Reggelin, S. Doerr, M. Klussmann, M. Schultz, M. Holbach, Proc. Natl. Acad. Sci. U.S.A 2004, 101, 5461-5466.

[29] a) M. Reggelin, M. Schultz, M. Holbach, Angew. Chem. Int. Ed. 2002 41, 1614-1617; b) C. A. Muller, T. Hoffart, M. Holbach, M. Reggelin, Macromolecules 2005, 38, 5375-5380.

[30] a) T. Yamamoto, M. Suginome, Angew. Chem. Int. Ed. 2009, 48, 539 542; b) T. Yamamoto, T. Yamada, Y. Nagata, M. Suginome, J. Am Chem. Soc. 2010, 132, 7899-7901.

[31] M. Suginome, T. Yamamoto, Y. Nagata, T. Yamada, Y. Akai, Pure Appl. Chem. 2012, 84, 1759-1769.

[32] The screw-sense excess adopted by helical covalent polymers quantitatively refers to the ratio of left-handed and right-handed fragments in a polymer chain. It is calculated by dividing the ellipticity value of a given polymer to the ellipticity value for the same polymer in a single-handed configuration (CD spectroscopy). The term "net helicity" employed in the context of supramolecular helices is equivalent.

[33] T. Yamamoto, Y. Akai, Y. Nagata, M. Suginome, Angew. Chem. Int. Ed. 2011, 50, 8844-8847.

[34] L. M. S. Takata, H. lida, K. Shimomura, K. Hayashi, A. A. dos Santos, E. Yashima, Macromol. Rapid. Commun. 2015, 36, 2047-2054.

[35] T. Yamamoto, T. Adachi, M. Suginome, ACS Macro Lett. 2013, 2, 790-793.

[36] Y. Nagata, T. Nishikawa, M. Suginome, J. Am. Chem. Soc. 2014, 136, 15901-15904.

[37] a) Y. Nagata, T. Kuroda, K. Takagi, M. Suginome, Chem. Sci. 2014, 5, 4953-4956; b) Y. Akai, L. Konnert, T. Yamamoto, M. Suginome, Chem. Commun. 2015, 51, 7211-7214
[38] T. Yamamoto, Y. Akai, M. Suginome, Angew. Chem. Int. Ed. 2014, 53, 12785-12788.

[39] Y. Akai, T. Yamamoto, Y. Nagata, T. Ohmura, M. Suginome, J. Am. Chem. Soc. 2012, 134, 11092-11095.

[40] Y. Yoshinaga, T. Yamamoto, M. Suginome, ACS Macro Lett. 2017, 6 , 705-710.

[41] T. Yamamoto, R. Murakami, M. Suginome, J. Am. Chem. Soc. 2017 139, 2557-2560.

[42] a) Y. Nagata, T. Nishikawa, M. Suginome, J. Am. Chem. Soc. 2015 137, 4070-4073; b) Y.-Z. Ke, Y. Nagata, T. Yamada, M. Suginome Angew. Chem. Int. Ed. 2015, 54, 9333-9337.

[43] Y. Nagata, T. Yamada, T. Adachi, Y. Akai, T. Yamamoto, M. Suginome, J. Am. Chem. Soc. 2013, 135, 10104-10113.

[44] T. Miyabe, Y. Hase, H. lida, K. Maeda, E. Yashima, Chirality 2009, 21, 44-50.

[45] T. Sato, K. Terao, A. Teramoto, M. Fujiki, Macromolecules 2002, 35 5355-5357.

[46] T. Yamamoto, R. Murakami, S. Komatsu, M. Suginome, J. Am. Chem. Soc. 2018, 140, 3867

[47] M. Ishikawa, K. Maeda, Y. Mitsutsuji, E. Yashima, J. Am. Chem. Soc 2004, 126, 732-733.

[48] a) M. Raynal, F. Portier, P. W. N. M. van Leeuwen, L. Bouteiller, J. Am. Chem. Soc. 2013, 135, 17687-17690; b) A. Desmarchelier, X. Caumes, M. Raynal, A. Vidal-Ferran, P. W. N. M. van Leeuwen, L. Bouteiller, J. Am. Chem. Soc. 2016, 138, 4908-4916.

[49] J. M. Zimbron, X. Caumes, Y. Li, C. M. Thomas, M. Raynal, L. Bouteiller, Angew. Chem. Int. Ed. 2017, 56, 14016-14019.

[50] a) Q. X. Jin, L. Zhang, H. Cao, T. Y. Wang, X. F. Zhu, J. Jiang, M. H. Liu, Langmuir 2011, 27, 13847-13853; b) J. Jiang, Y. Meng, L. Zhang, M. H. Liu, J. Am. Chem. Soc. 2016, 138, 15629-15635; c) C. H. Yuan, J. Jiang, H. Sun, D. C. Wang, Y. H. Hu, M. H. Liu, ChemCatChem 2018 10, 2190-2194; d) H. Sun, J. Jiang, Y. M. Sun, Q. W. Zhang, M. H. Liu, Chem. Commun. 2019, 55, 3254-3257.

[51] Y. Li, X. Caumes, M. Raynal, L. Bouteiller, Chem. Commun. 2019, 55 2162-2165.

[52] S. Cantekin, T. F. A. de Greef, A. R. A. Palmans, Chem. Soc. Rev 2012, 41, 6125-6137.

[53] a) M. de Loos, J. H. van Esch, R. M. Kellogg, B. L. Feringa Tetrahedron 2007, 63, 7285-7301; b) M. A. J. Veld, D. Haveman, A. R A. Palmans, E. W. Meijer, Soft Matter 2011, 7, 524-531; c) A Desmarchelier, M. Raynal, P. Brocorens, N. Vanthuyne, L. Bouteiller Chem Commun 2015, 51, 7397-7400; d) A. Desmarchelier, B. G. Alvarenga, X. Caumes, L. Dubreucq, C. Troufflard, M. Tessier, N. Vanthuyne, J. Ide, T. Maistriaux, D. Beljonne, P. Brocorens, R Lazzaroni, M. Raynal, L. Bouteiller, Soft Matter 2016, 12, 7824-7838; e) X. Caumes, A. Baldi, G. Gontard, P. Brocorens, R. Lazzaroni, N Vanthuyne, C. Troufflard, M. Raynal, L. Bouteiller, Chem. Commun 2016, 52, 13369-13372; f) G. Basuyaux, A. Desmarchelier, G. Gontard N. Vanthuyne, J. Moussa, H. Amouri, M. Raynal, L. Bouteiller, Chem. Commun. 2019, DOI: 10.1039/c1039cc03906f.

[54] a) Y. Nagata, T. Nishikawa, M. Suginome, ACS Macro Lett. 2016, 5 , 519-522; b) T. Yamada, Y. Nagata, M. Suginome, Chem. Commun. 2010, 46, 4914-4916; c) Y. Nagata, T. Nishikawa, M. Suginome, Chem. Commun. 2018, 54, 6867-6870.

[55] For a probing of the origin of the solvent effect by means of small angle neutron scattering analysis see: Y. Nagata, T. Nishikawa, M. Suginom, S. Sato, M. Sugiyama, L. Porcar, A. Martel, R. Inoue, N. Sato, J. Am Chem. Soc. 2018, 140, 2722-2726.

[56] a) L. L. Lin, X. M. Feng, Chem. Eur. J. 2017, 23, 6464-6482; b) S Krautwald, E. M. Carreira, J. Am. Chem. Soc. 2017, 139, 5627-5639.

[57] G. W. Coates, R. M. Waymouth, Science 1995, 267, 217-219. 